\title{
TRANSFORMATION OF THE BIOSPHERE
}

The effects of human intervention are now apparent on more than half of Earth's ice-free land mass.

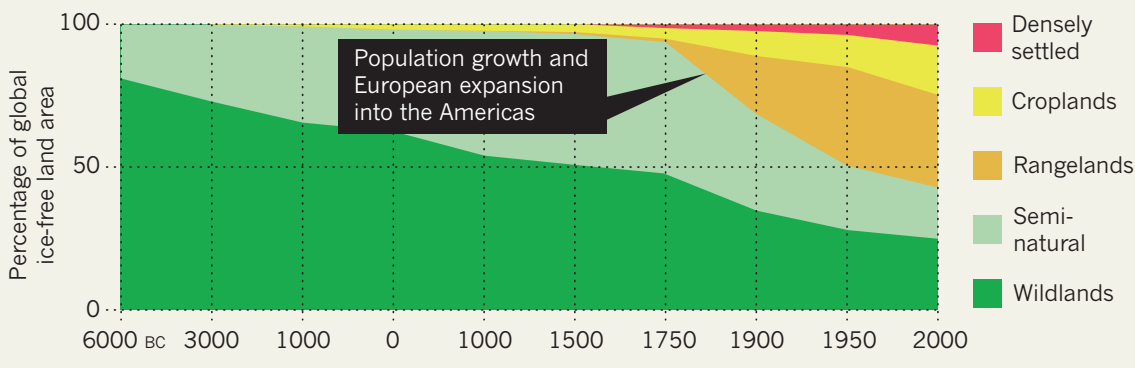

EARTH SCIENCE

\section{Human influence comes of age}

\section{Geologists debate epoch to mark effects of Homo sapiens.}

\section{BY NICOLA JONES}

$\mathrm{H}$ umanity's profound impact on this planet is hard to deny, but is it big enough to merit its own geological epoch? This is the question facing geoscientists gathered in London this week to debate the validity and definition of the 'Anthropocene', a proposed new epoch characterized by human effects on the geological record.

"We are in the process of formalizing it," says Michael Ellis, head of the climate-change programme of the British Geological Survey in Nottingham, who coordinated the 11 May meeting. He and others hope that adopting the term will shift the thinking of policy-makers. "It should remind them of the global and significant impact that humans have," says Ellis.

But not everyone is behind the idea. "Some think it premature, perhaps hubristic, perhaps nonsensical," says Jan Zalasiewicz, a stratigrapher at the University of Leicester, UK, and a co-convener of the meeting. Zalasiewicz, who declares himself "officially very firmly sitting on the fence", also chairs a working group investigating the proposal for the International Commission on Stratigraphy (ICS) - the body that oversees designations of geological time.

The term Anthropocene was first coined in 2000 by Nobel laureate Paul Crutzen, now at the Max Planck Institute for Chemistry in Mainz, Germany, and his colleagues. It then began appearing in peer-reviewed papers as if it were a technical term rather than scientific slang.

The "evidence for the prosecution", as Zalasiewicz puts it, is compelling. Through food production and urbanization, humans have altered more than half of the planet's icefree land mass $^{1}$ (see 'Transformation of the biosphere'), and are moving as much as an order of magnitude more rock and soil around than are natural processes ${ }^{2}$. Rising carbon dioxide levels in the atmosphere are expected to make the ocean $0.3-0.4 \mathrm{pH}$ points more acidic by the end of this century. That will dissolve light-coloured carbonate shells and sea-floor rocks for about 1,000 years, leaving a dark band in the seafloor sediment that will be obvious to future geologists. A similar dark stripe identifies the Palaeocene-Eocene Thermal Maximum about 55 million years ago, when global temperatures rose by some $6^{\circ} \mathrm{C}$ in 20,000 years. A similar temperature jump could happen by 2100 , according to some high-emissions scenarios ${ }^{3}$.
The fossil record will show upheavals too. Some $20 \%$ of species living in large areas are now invasive, says Zalasiewicz. "Globally that's a completely novel change." And a review published in Nature in March $^{4}$ concluded that the disappearance of the species now listed as 'critically endangered' would qualify as a mass extinction on a level seen only five times in the past 540 million years - and all of those mark transitions between geological time periods.

Some at the ICS are wary of formalizing a new epoch. "My main concern is that those who promote it have not given it the careful scientific consideration and evaluation it needs," says Stan Finney, chair of the ICS and a geologist at California State University in Long Beach. He eschews the notion of focusing on the term simply to "generate publicity".

Others point out that an epoch typically lasts tens of millions of years. Our current epoch, the Holocene, began only 11,700 years ago. Declaring the start of a new epoch would compress the geological timeline to what some say is a ridiculous extent. Advocates of the Anthropocene, however, say that it is natural to divide recent history into smaller, more detailed chunks. A less controversial alternative would be to declare the Anthropocene a new 'age': a subdivision of an epoch.

If scientists can agree in principle that a new time division is justified, they will have to settle on a geological marker for its start. Some suggest the pollen of cultivated plants, arguing that mankind's fingerprint can be seen $5,000-10,000$ years ago with the beginnings of agriculture. Others support the rise in the levels of greenhouse gases and air pollution in the latter part of the eighteenth century, as industrialization began. A third group would start with the flicker of radioactive isotopes in 1945 , marking the invention of nuclear weapons.

Should the working group decide that the Anthropocene epoch has merit, it will go to an ICS vote. But the whole process will take time - defining other geological periods has sometimes taken decades. In the meantime, Zalasiewicz says, "the formalization is the excuse to try to do some very interesting science", comparing Earth's current changes to those of the past.

1. Ellis, E. C. Phil. Trans. R. Soc. A 369, 1010-1035 (2011)

2. Zalasiewicz, J., Williams, M., Haywood, A. \& Ellis, M. Phil. Trans. R. Soc. A 369, 1036-1055 (2011).

3. IPCC Climate Change 2007: The Physical Science Basis (IPCC, 2007)

4. Barnosky, A. D. et al. Nature 471, 51-57 (2011)

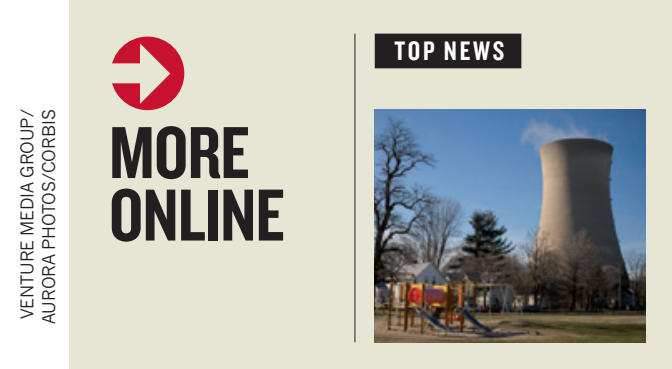

Nuclear power plants cleared of leukaemia link go.nature. com/u2ehtq

\section{OTHER NEWS}

- Fracturing rock to extract natural gas raises methane in drinking water go.nature.com/zhas 20

- How to get funded when success rates fall go.nature.com/qytird

- Australia's new chief scientist reveals his plans go.nature.com/qqgutl

\section{PODCAST}

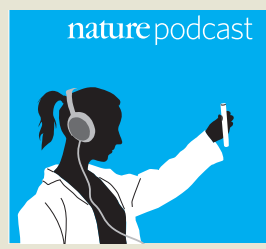

In the backyard: new type of fungus found in university pond go.nature. com/xtlrak 